\title{
Is There Natural Killer Cell Memory and Can It Be Harnessed by Vaccination?
}

\section{Natural Killer Cells in Vaccination}

\author{
Harold R. Neely, ${ }^{1}$ Irina B. Mazo, ${ }^{1}$ Carmen Gerlach, ${ }^{1}$ and Ulrich H. von Andrian ${ }^{1,2}$ \\ ${ }^{1}$ Department of Microbiology and Immunobiology, Harvard Medical School, Boston, Massachusetts 02115 \\ ${ }^{2}$ The Ragon Institute of MGH, MIT and Harvard, Cambridge, Massachusetts 02139 \\ Correspondence: uva@hms.harvard.edu
}

\begin{abstract}
Natural killer (NK) cells have historically been considered to be a part of the innate immune system, exerting a rapid response against pathogens and tumors in an antigen (Ag)-independent manner. However, over the past decade, evidence has accumulated suggesting that at least some NK cells display certain characteristics of adaptive immune cells. Indeed, NK cells can learn and remember encounters with a variety of Ags, including chemical haptens and viruses. Upon rechallenge, memory NK cells mount potent recall responses selectively to those Ags. This phenomenon, traditionally termed "immunological memory," has been reported in mice, nonhuman primates, and even humans and appears to be concentrated in discrete NK cell subsets. Because immunological memory protects against recurrent infections and is the central goal of active vaccination, it is crucial to define the mechanisms and consequences of NK cell memory. Here, we summarize the different kinds of memory responses that have been attributed to specific NK cell subsets and discuss the possibility to harness NK cell memory for vaccination purposes.
\end{abstract}

\section{GREAT DEBATES}

What are the most interesting topics likely to come up over dinner or drinks with your colleagues? Or, more importantly, what are the topics that don't come up because they are a little too controversial? In Immune Memory and Vaccines: Great Debates, Editors Rafi Ahmed and Shane Crotty have put together a collection of articles on such questions, written by thought leaders in these fields, with the freedom to talk about the issues as they see fit. This short, innovative format aims to bring a fresh perspective by encouraging authors to be opinionated, focus on what is most interesting and current, and avoid restating introductory material covered in many other reviews.

The Editors posed 13 interesting questions critical for our understanding of vaccines and immune memory to a broad group of experts in the field. In each case, several different perspectives are provided. Note that while each author knew that there were additional scientists addressing the same question, they did not know who these authors were, which ensured the independence of the opinions and perspectives expressed in each article. Our hope is that readers enjoy these articles and that they trigger many more conversations on these important topics.

Editors: Shane Crotty and Rafi Ahmed

Additional Perspectives on Immune Memory and Vaccines: Great Debates available at www.cshperspectives.org

Copyright (C 2018 Cold Spring Harbor Laboratory Press; all rights reserved; doi: 10.1101/cshperspect.a029488

Cite this article as Cold Spring Harb Perspect Biol 2018;10:a029488 
H.R. Neely et al.

$\mathrm{N}$ atural killer (NK) cells were discovered over 40 years ago as a population of lymphocytes that could lyse sheep red blood cells and tumor cells "naturally" (i.e., without requiring prior activation) (Thornthwaite and Leif 1974; Herberman et al. 1975; Kiessling et al. 1975). Traditionally, NK cells have been classified as innate immune cells that recognize their targets through a variety of germline-encoded receptors. However, there is accumulating evidence that at least some NK cells possess properties that characterize adaptive immunity, such as the capacity to acquire long-lived antigen (Ag)-specific immunologic memory (Paust and von Andrian 2011).

Indeed, recent studies have shown that certain subsets of NK cells can specifically "remember" diverse viral and hapten-based Ags, raising the intriguing possibility that NK cell memory might be harnessed for new vaccination strategies, and indeed that NK memory might even arise in response to traditional and established vaccines. Here, we examine the arguments for and against a potential role for NK cells during prophylactic and therapeutic vaccination in light of the known heterogeneities within the NK cell lineage and, more specifically, the heterogeneity of apparent immunologic recall responses that have been observed among NK cell subsets.

\section{NK CELL SUBSETS}

NK cells are classified as belonging to group 1 of the innate lymphoid cell (ILC) family (Spits et al. 2013), as their development and function does not require recombination-activating gene (RAG)-mediated V(D)J recombination of Agreceptor gene segments. Rather, at the population level, both murine and human NK cells express a broad repertoire of germline-encoded activating and inhibitory receptors, although any individual NK cell usually expresses only a small and highly variable selection of these receptors. Prominent examples of such receptors are the Ly49 family in mice, the killer-cell immunoglobulin-like receptor (KIR) family in humans, and the NKG2 genes in both species. Depending on the expression profile of these and other receptors, NK cells have been subdivided into a multitude of subsets (Lanier 2005; Middleton and Gonzelez 2010; Schenkel et al. 2013), and have been further subdivided based on distinct developmental pathways, gene expression patterns, anatomic localization, and function (reviewed in Yu et al. 2013; Sojka et al. 2014; Björkström et al. 2016; Simonetta et al. 2016). The relative contributions of several of these subsets to memory-like NK cell responses are discussed below.

Whereas NK cell phenotypes often differ depending on the tissue in which they reside, it is unclear whether tissue-specific factors drive phenotypic changes on resident NK cells, or whether distinct tissues selectively recruit a priori distinct NK cell subsets (Spits et al. 2016). This is particularly relevant in the context of NK cell memory, as the capacity to form memory of certain Ags differs between liver-resident and nonhepatic (e.g., splenic) NK cells. Both mouse and human liver harbors a prominent population of $\mathrm{CXCR6}^{+} \mathrm{NK}$ cells (Paust et al. 2010; Stegmann et al. 2016). In hapten-immunized mice, this hepatic population is highly enriched for Ag-specific memory cells, whereas hapten-specific memory NK cells are rare or absent among NK populations in most nonhepatic tissues.

The multiplicity of NK cell subsets presents both a challenge and a potential opportunity with respect to harnessing NK cells for vaccination. To this end, it will be necessary to investigate the properties of each subset for a more complete understanding of their relative capacity to acquire, retain, and recall protective memory of vaccine Ags.

\section{MEMORY NK CELLS IN HEALTH AND DISEASE}

\section{What Is Immunological Memory?}

A hallmark of immunological memory is the ability to mount qualitatively and/or quantitatively distinct responses to an initial versus subsequent challenge(s). Indeed, when compared to naïve NK cells, memory NK cells show a higher proliferation rate, cytokine production, and cy- 
Is There Natural Killer Cell Memory and Can It Be Harnessed by Vaccination?

totoxicity on challenge with a previously encountered stimulus (Sun et al. 2009). However, studies in mice suggest that there are several different "flavors" of NK cell memory (Cerwenka and Lanier 2016), which differ with regard to the sensitizing agent(s), the ensuing cellular response, and the dependence on specific Ag recognition (Fig. 1; Table 1).

\section{Ag-Nonspecific Memory-Like NK Cells}

Ag-nonspecific memory-like NK cells have been defined in both mice and humans. Murine cytokine-induced memory-like NK cells were originally described by Cooper et al. (2009). In this study, splenic NK cells were activated ex vivo with the cytokines IL-12, IL-15, and IL-18.

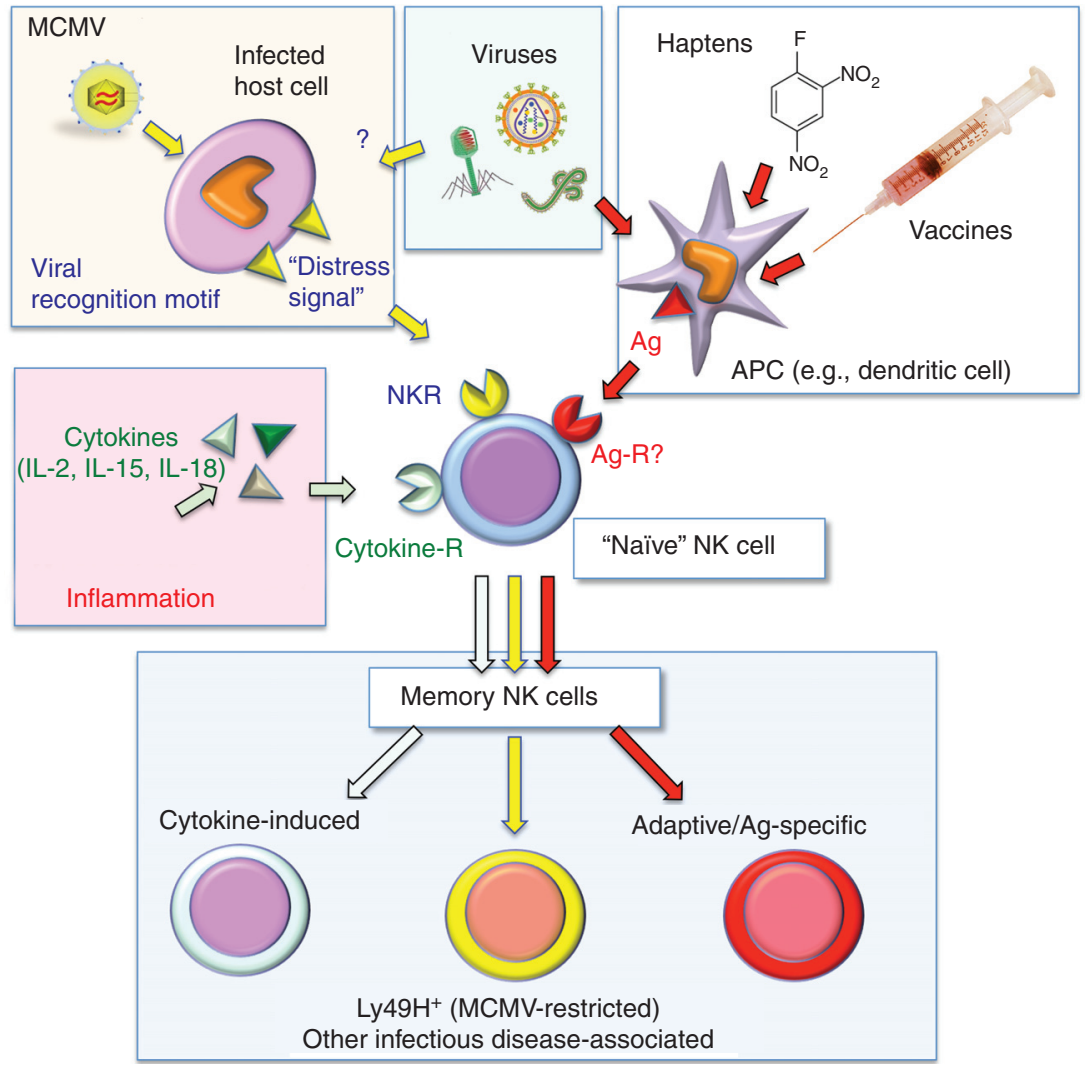

Figure 1. Mechanisms of natural killer (NK)-cell activation resulting in the induction of NK-mediated immunological memory. Upon activation by a variety of stimuli, "naïve" NK cells adopt a memory phenotype, characterized by the capacity to mount a qualitatively and/or quantitatively enhanced immune response to secondary exposure to the same (or a similar) stimulus. The type of memory NK cell elicited depends on the activating stimulus. For example, certain inflammation-induced cytokines, specifically interleukin (IL)-2, IL-15, and IL-18, acting on NK-cell-expressed cytokine receptors (middle, left) induce memory-like NK cells that are not restricted to specific antigens (Ags). Infection with certain viruses (such as mouse cytomegalovirus [MCMV] in C57BL6 mice) induces expression of virally encoded recognition motifs (e.g., MCMV-m157) and other activating distress signals (e.g., NKG2D ligands) on the host-cell surface that are recognized by germline-encoded NK cell receptors (NKRs; e.g., Ly49H). Finally, some NK cells have the capacity to specifically recognize and remember highly diverse microbial or hapten-based immunizing Ags presented by dendritic cells and other antigen-presenting cells (APCs). The receptor(s) used by NK cells to detect such Ags (Ag-R) are as yet undefined. It should be noted that although a single naïve NK cell is shown to give rise to memory in response to all stimuli, naïve NK cells actually comprise a large variety of discrete subsets, and the ability to generate specific types of memory varies greatly between subsets. 
H.R. Neely et al.

Table 1. Memory and "memory-like" natural killer (NK) cell involvement in infectious diseases, and experimental evidence for the establishment of NK-cell-associated immunological memory to indicated pathogens in humans, nonhuman primates, and mice

\begin{tabular}{|c|c|c|}
\hline Disease/pathogen & Experimental evidence & References \\
\hline \multicolumn{3}{|l|}{ Human } \\
\hline HCMV & $\begin{array}{l}\text { Expansion of "memory-like" } \\
\text { CD } 57^{+} \text {CD } 56^{\text {dim }} \text { NKG2ChiSiglec7-NKG2A-KIRs } \\
\text { NK population in serologically positive individuals }\end{array}$ & $\begin{array}{l}\text { Björkström et al. 2011; Lopez- } \\
\text { Vergès et al. 2011; Foley et al. } \\
\text { 2012; Lee et al. } 2015\end{array}$ \\
\hline Hantavirus* & $\begin{array}{l}\text { High frequency of } \mathrm{CD} 56^{\mathrm{dim}} \mathrm{CD} 16^{+} \mathrm{NKG} 2 \mathrm{C}^{+} \text {subset of } \\
\text { NK cells, which persisted for at least } 60 \text { days after } \\
\text { infection }\end{array}$ & Béziat et al. 2012 \\
\hline $\mathrm{HBV}^{*}$ and $\mathrm{HCV}^{*}$ & $\begin{array}{l}\text { Clonal expansion of } \mathrm{CD} 56^{\mathrm{dim}} \mathrm{NKG}^{-\mathrm{C}^{+}} \mathrm{KIRs}^{+} \mathrm{NK} \\
\text { subset in infected individuals }\end{array}$ & \\
\hline $\begin{array}{l}\text { Chikungunya } \\
\text { virus* }\end{array}$ & $\begin{array}{l}\text { Increased frequency of CD } 56^{+} \mathrm{NKG} 2 \mathrm{C}^{+} \mathrm{ILT}-2^{+} \mathrm{NKG} 2 \mathrm{~A}- \\
\mathrm{NK} \text { cells with high cytotoxic activity }\end{array}$ & \\
\hline $\mathrm{HIV}-1^{*}$ & $\begin{array}{l}\text { Expansion of } \mathrm{NKG} 2 \mathrm{C}^{+} \mathrm{NK} \text { population in patients with } \\
\text { chronic viremia }\end{array}$ & Petitdemange et al. 2011 \\
\hline HIV-1 & $\begin{array}{l}\mathrm{CD} 56-\mathrm{CD} 16^{+} \mathrm{CD}^{+} \mathrm{NK} \text { population showed evidence of } \\
\text { a recent engagement with target cells and was } \\
\text { expanded in HIV-infected individuals }\end{array}$ & Brunetta et al. 2010 \\
\hline Influenza A & $\begin{array}{l}\text { Increased IFN- } \gamma \text { production by NKp } 46 \\
\text { (intracellular) }{ }^{+} \mathrm{CD} 56^{\mathrm{dim}} \mathrm{NK} \text { cells from vaccinated } \\
\text { individuals after restimulation with influenza virus; } \\
\text { increased cytotoxic activity was virus-specific }\end{array}$ & $\begin{array}{l}\text { Milush et al. 2013; York et al. } \\
2013\end{array}$ \\
\hline $\begin{array}{l}\text { Mycobacterium } \\
\text { tuberculosis }\end{array}$ & $\begin{array}{l}\text { "Memory-like" CD } 45 \mathrm{RO}^{+} \mathrm{NK} \text { cells from pleural fluid of } \\
\text { tuberculosis patients produced elevated amount of } \\
\text { IFN- } \gamma \text { and IL-22 in response to BCG when compared } \\
\text { to peripheral blood NKs }\end{array}$ & Dou et al. 2015 \\
\hline
\end{tabular}

Primates

SIV

NK cell subset expressing NKG2A and NKG2C isolated

Fu et al. 2011, 2016

from spleens and livers of SIV-infected or Ad26vaccinated rhesus macaques kill autologous DCs in vitro in an Ag-dependent manner

Mouse
MCMV

Rapid expansion and long persistence of $\mathrm{Ly} 49 \mathrm{H}^{+} \mathrm{NK}$ cells after MCMV infection; adoptive transfer of these NK cells into a naïve host followed by MCMV infection mediates Ag-specific proliferation

HSV-2

Stimulation with HSV-2 Ags led to a higher IFN- $\gamma$ Sun et al. 2009 production in NK cells that were exposed to HSV-2 30 days prior

Vaccinia virus (VV) Thy $1^{+}$hepatic NK cells isolated from VV-infected mice Abdul-Careem et al. 2012 could protect from a lethal dose of the virus on adoptive transfer

Influenza A

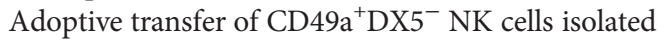
from livers of influenza-infected mice protected secondary host against influenza

Influenza A, VSV, Adoptive transfer of virus-sensitized hepatic NK cells HIV into naïve recipient enhanced survival of the mice after lethal dose of the sensitizing virus but not of the irrelevant virus 
Is There Natural Killer Cell Memory and Can It Be Harnessed by Vaccination?

Table 1. Continued

\begin{tabular}{lcc}
\hline Disease/pathogen & \multicolumn{1}{c}{ Experimental evidence } & References \\
\hline Ehrlichia & Hepatic and splenic NK cells isolated from Ehrlichia & Paust et al. 2010; \\
& $\begin{array}{l}\text { muris-infected mice and adoptively transferred into } \\
\text { RAG2 } 2^{-1} \mathrm{gc}^{-1-} \text { naïve recipients protected secondary }\end{array}$ & Habib et al. 2016 \\
& \\
& host against Ixodes ovatus Ehrlichia & \\
\hline
\end{tabular}

NK, Natural killer; HBV, hepatitis B virus; HCV, hepatitis C virus; HIV, human immunodeficiency virus; IFN- $\gamma$, interferon $\gamma$; IL, interleukin; BCG, bacille Calmette-Guérin; SIV, simian immunodeficiency virus; DC, dendritic cell; Ag, antigen; MCMV, mouse cytomegalovirus; HSV-2, herpes simplex virus type 2; VSV, vesicular stomatitis virus.

${ }^{*}$ Most of the patients were also serologically positive for human cytomegalovirus (HCMV).

On transfer to a naïve host, the cells were shown to return to a quiescent state, but displayed an intrinsic capacity for more efficient proliferation and interferon $\gamma($ IFN- $\gamma)$ production after reactivation (Cooper et al. 2009). Subsequent reports confirmed the existence of cytokine-induced memory cells among CD56 ${ }^{\mathrm{dim}}$ human NK cells (Romee et al. 2012). Although the initial studies in humans did not show increased killing capacity of cytokine-dependent memory NK cells, a recent clinical study reported enhanced activity of cytokine-preconditioned human NK cells against acute myeloid leukemia (Romee et al. 2015).

NK cells undergoing homeostatic proliferation in NK-deficient hosts represent another arm of Ag-nonspecific NK cell memory. In a lymphopenic host, adoptively transferred NK cells undergo proliferation and self-renew at steady state (Prlic et al. 2003). The mechanism for this homeostatic proliferation is unclear. A recent study indicates that Krüppel-like factor 2 (KLF2) limits homeostatic expansion of immature NK cells in a cell-intrinsic manner (Rabacal et al. 2016), but instructs mature NK cells to home to IL-15-rich niches (e.g., liver and bone marrow), which is necessary for long-term NKcell survival (Prlic et al. 2003; Ranson et al. 2003; Jamieson et al. 2004). Homeostatically expanded NK cells persist in tissues for a long time without loss of activity (Sun et al. 2011).

Ag-specific NK cell memory requiring a germline-encoded $\mathrm{Ag}$ receptor has been shown for NK cells in C57BL/6 mice specific to mouse cytomegalovirus (MCMV) (Table 1). MCMV has been shown to induce rapid clonal expansion of an NK subset expressing the activating receptor Ly49H, which recognizes the MCMVencoded protein m157 (Sun et al. 2009). The known identity of both virus receptor and ligand in this model has permitted extensive and indepth investigation of molecular mechanism(s) triggering generation and maintenance of MCMV-specific memory NK cells (reviewed in O'Sullivan et al. 2015; Cerwenka and Lanier 2016).

Similar to MCMV, human cytomegalovirus (HCMV) infection is associated with the generation of a subset of NK memory cells (Table 1). Indeed, the majority of data regarding the role of potential NK-cell-mediated immunological memory in human infection concerns HCMV. Seropositivity for HCMV is frequently accompanied by higher frequency of an NK subset expressing the activating receptor CD94/ NKG2C (Rolle et al. 2013). During acute infection, the proportion of $\mathrm{CD} 94 / \mathrm{NKG}_{2} \mathrm{C}^{+}$cells within the $\mathrm{NK}$ cell pool increases, and on HCMV reactivation, this population increases again and expresses higher amounts of IFN- $\gamma$ (Foley et al. 2012). This enhanced functionality on encounter of a recall Ag constitutes a hallmark of adaptive immunity. Further, HCMVassociated $\mathrm{NKG}_{2} \mathrm{C}^{+} \mathrm{NK}$ cells have also been shown to harbor epigenetic signatures similar to those observed in memory $\mathrm{CD}^{+} \mathrm{T}$ cells (Lee et al. 2015; Schlums et al. 2015), suggesting further differentiation from "naïve" or conventional NK cells. However, unlike in the case of MCMV-specific memory NK cells, the exact mechanism underlying generation of HCMVtropic memory-like NK cells is still unknown, although a role for HLA-E and activating KIRs has been reported (Della Chiesa et al. 2013). Of 
H.R. Neely et al.

note, NKG2C is not necessary for NK-cell-mediated responses to HCMV per se (Della Chiesa et al. 2014).

A similar NK cell subset expansion has also been observed in human immunodeficiency virus (HIV) infection (Milush et al. 2013). In $\mathrm{HIV}$-infected individuals, $\mathrm{CD} 7{ }^{+} \mathrm{CD} 56^{\text {neg }} \mathrm{CD} 16^{+}$ NK cells show evidence of activation and recent engagement of target cells. However, further study is warranted to determine whether these cells represent a memory subset or simply an acutely expanded population.

\section{Ag-Specific Memory of Highly Diverse Ags}

The first observation of NK-cell-mediated adaptive immune responses came from studies utilizing a hapten-induced model of contact hypersensitivity (CHS) (O'Leary et al. 2006). In these experiments, a hapten was applied to intact skin during sensitization and challenge, and the magnitude of the secondary immune response was measured by the intensity of skin inflammation on reexposure to the same Ag. A positive Ag-specific CHS response to several haptens has been shown in mice of various genetic backgrounds in the complete absence of $\mathrm{T}$ and $\mathrm{B}$ cells (Table 2). Adoptive transfer experiments showed that only NK cells localized in the liver, but not in the spleen, were necessary and sufficient to transfer hapten-specific memory from immunized to naïve animals (O'Leary et al. 2006; Rouzaire et al. 2012). Further reports determined that NK-cell-dependent CHS requires the presence of IL-12, IFN- $\gamma$, and IFN- $\alpha$ (Majewska-Szczepanik et al. 2013) and signaling via CXCL16, a chemokine that is richly expressed in liver sinusoids, and its receptor CXCR6 that is expressed on a subset of liver NK cells (Paust et al. 2010). More recently, experiments used monobenzone, a prohapten that is exclusively metabolized by melanocytes and haptenizes melanocyte-specific Ags (van den Boorn et al. 2016). In this study, hepatic memory NK cells not only mediated a CHS response, but also exerted antitumor activity in a model of experimental melanoma. Additional experiments suggested a role for the NLRP3 inflammasome as a critical proinflammatory checkpoint in the induction of monobenzone-specific memory NK cells (van den Boorn et al. 2016).

In accordance with the shown diversity of specificities among hepatic NK cells for different chemical haptens, murine hepatic NK cells can also develop memory of other exogenous Ags. Studies have shown that mouse NK cells, which reside in the liver but not the spleen, can acquire long-lived memory of several viral Ags other than MCMV (Table 3), including vesicular stomatitis virus (VSV), influenza A, and HIV-1 (Paust et al. 2010). Importantly, cross-protective memory was not observed among different viruses, indicative of a truly Ag-restricted memory response. Memory NK cells in this study were able to protect $\mathrm{T}$ - and B-cell-deficient animals, at least in part, against subsequent challenge with virus, suggesting a potential utility of memory NK cells in vaccination (Table 1).

Table 2. Antigen (Ag)-specific memory mediated by murine hepatic natural killer (NK) cells in response to haptens

\begin{tabular}{|c|c|c|c|c|}
\hline \multirow[b]{2}{*}{ Challenge agent } & \multicolumn{4}{|c|}{ Sensitizing agent } \\
\hline & OXA & DNFB & Monobenzone & Picryl chloride \\
\hline OXA & + & - & n.d. & n.d. \\
\hline DNFB & - & + & n.d. & n.d. \\
\hline Monobenzone & - & n.d. & + & n.d. \\
\hline Picryl chloride & n.d. & n.d. & n.d. & + \\
\hline
\end{tabular}

Ability of individual haptens to elicit an enhanced contact hypersensitivity (CHS) response on challenge with either sensitizing hapten or previously unencountered hapten. Sensitizing agent shown in top row, and challenge agent shown in left column (see also O'Leary et al. 2006 and Paust et al. 2010).

+, enhanced CHS response relative to primary exposure; -, no difference from baseline response; n.d., not determined; OXA, oxazolone; DNFB, 1-fluoro-2,4-dinitrobenzene. 
Is There Natural Killer Cell Memory and Can It Be Harnessed by Vaccination?

Table 3. Antigen (Ag)-specific recall responses mediated by murine hepatic natural killer (NK) cells in response to viral Ags

\begin{tabular}{llcc}
\hline & \multicolumn{3}{c}{ Immunizing Ag } \\
\cline { 2 - 4 } Challenge Ag & HIV & Influenza & VSV \\
\hline HIV & + & - & - \\
Influenza & - & + & - \\
VSV & n.d. & - & + \\
\hline
\end{tabular}

T- and B-cell-deficient mice were immunized with inactivated virus (VSV) or with virus-like particles (VLPs) composed of recombinant Ags from either human immunodeficiency virus (HIV)-1 or influenza A. The ability of NK cells to mediate adaptive immune responses to the indicated viral $\mathrm{Ag}$ was measured as delayed-type hypersensitivity response on secondary challenge and/or survival after lethal infection with influenza or VSV. Immunizing viral Ags are shown in top row, and challenge Ags are shown in left column (see also Paust et al. 2010).

+ , enhanced recall response relative to primary exposure; -, baseline (irritant) response; n.d., not determined.

A role of NK cells in protective memory against bacteria has not been clearly shown so far. A recent study provided evidence that primary infection of mice with Ehrlichia muris mediated long-term protection against a second challenge with highly virulent Ixodes ovatus Ehrlichis, and this protection was orchestrated by NK cells (Habib et al. 2016). However, the suggested mechanism was attributed to a rise of cytokine-dependent memory-like NK cells during the primary infection rather than to a direct recognition of a pathogen by an unknown receptor expressed on NK cells.

Whereas bona fide NK-cell-mediated adaptive immunity (i.e., acquired memory and Ag specificity) has not yet been shown in humans, there is evidence for virus-specific NK cell memory in nonhuman primates (Reeves et al. 2015). Ag-specific memory NK cells were observed in rhesus macaques after immunization with adenoviral vaccines expressing either simian immunodeficiency virus (SIV) or HIV Ags (Reeves et al. 2015). Robust Ag-specific NK cell memory could be detected as late as 5 years after immunization. Unlike in mice, NK cell memory in nonhuman primates was not confined to hepatic NK cells, but was also evident in splenic NK cells (Table 1).

Regardless of species, there is now mounting evidence that some mammalian NK cells can give rise to memory cells that appear to be highly specific for a variety of Ags, even for Ags that seem unlikely to have exerted the prerequisite evolutionary pressure for germline-encoded pattern receptors to arise (for example, following immunization with the gag or env proteins of HIV-1 mouse memory NK cells display exquisite specificity for these viral Ags, even though HIV-1 is not a mouse pathogen). The mechanism(s) by which NK cells recognize these Ags are still a mystery.

\section{Harnessing NK Cell Memory for Vaccination}

In the decades since their discovery, the importance of innate functions of NK cells in the control/resolution of human disease has been well established. More recently, evidence for the potential of NK cells to both mediate Ag-specific responses and to "remember" previously encountered Ags/pathogens has steadily increased. As the greatest potential for vaccines that elicit NK cell memory lies in the induction of $\mathrm{Ag}$ specific memory, these recent studies have brought NK-cell-mediated vaccination into the realm of possibility.

Ag-specific memory (although without antigenic diversity) has so far only been described in detail in the mouse, in the Ly49H interaction with the MCMV-encoded m157. In humans, HCMV infection is associated with increased numbers of CD94/NKD2 $\mathrm{C}^{+} \mathrm{NK}$ cells, suggesting that a similar Ag-specific interaction between this activating NK receptor and an HCMV-derived counter-receptor may exist, but the exact ligand for $\mathrm{CD} 94 / \mathrm{NKD} 2 \mathrm{C}$ is yet to be determined. Nevertheless, it seems plausible that a potential HCMV vaccine (Sung and Schleiss 2010) will induce not only memory $\mathrm{B}$ and $\mathrm{T}$ cells, but also memory NK cells that may contribute to protection. To exploit this type of memory further in vaccinations, it is crucial to identify more receptor-ligand pairs (if they exist) that have the ability to induce NK cell memory.

Whereas identification of receptor/ligand pairs comparable to those found in the MCMV system (and presumed to exist in the HCMV system) will undoubtedly be useful in the treatment and prevention of human disease, 
H.R. Neely et al.

the potential diversity of such vaccines and therapies is necessarily limited by the repertoire of germline-encoded receptors for pathogen-encoded ligands. Additionally, the study of such systems in experimental models is complicated by the rapid evolution of pattern receptors and consequent differences between mouse and human-activating/inhibitory NK receptors. Humanized mice could potentially offer a powerful alternative to study and characterize human NK receptor/pathogen interactions in vivo, but these models will likely require extensive genetic engineering to optimize interactions of human NK cells with surface receptors and cytokines produced by murine hosts.

The only type of immunological memory that can be fully exploited by vaccines relies on Ag specificity against a diversity of Ags. Indeed, a broad, preimmune repertoire of antigenic specificities is a prerequisite for NK cells to be considered a viable target lymphocyte population in vaccination. To date, it has been shown that murine liver-resident NK cells can form Ag-restricted memory against various haptens, VSV, influenza A, vaccinia virus, and HIV-1. Because of the variety of reactivities identified so far, it is conceivable-and perhaps likelythat many more Ags can elicit this type of NKcell-mediated memory.

One caveat that may temper enthusiasm for the development of NK-cell-mediated vaccines lies in the fact that Ag-specific, NK-mediated immunity has not, to date, been shown in humans. However, potentially memory-capable NK cells are most likely rare in peripheral blood, if present at all; the identification of liver-resident CXCR6 ${ }^{+}$NK cells in humans (Stegmann et al. 2016) raises the possibility that a comparable population to the murine hepatic memory NK cells might exist. Furthermore, the fact that nonhuman primates mount NK-cell-mediated memory responses against SIV- and HIV-derived Ags is very promising in this regard.

\section{Challenges, Obstacles, and Open Questions}

Although the phenomenon of NK cell memory is now well established, many questions regarding its pathophysiological role and, in particular, the impact of vaccines on NK cells remain to be answered. For example, if mammalian NK cells can develop specific memory to a wide variety of Ags, should not at least some of our existing vaccines elicit such memory? If the answer is "yes" (which seems likely), why is there so little experimental or clinical evidence? One plausible reason is that, until very recently, investigators have lacked robust assays to evaluate Ag-specific recall responses by NK cells.

The current lack of molecular understanding of both the mechanism(s) of Ag recognition by and the mode(s) of $\mathrm{Ag}$ presentation to NK cells have been major obstacles toward developing straightforward approaches, such as the enumeration and characterization of Ag-specific NK cell subsets by quantitative techniques, such as flow cytometry. Thus, the detection of NK cell recall responses to vaccine Ags requires more complex measurements of functional responses by NK cells to a suitable target cell presenting the recall Ag. As discussed above, this approach was taken recently to show long-lived NK memory in nonhuman primates (Reeves et al. 2015). An analogous strategy was used previously in mice to study NK memory to several viral Ags (Paust et al. 2010). Both studies used in vitro cocultures of purified splenic or hepatic NK cells with a mixture of autologous dendritic cells (DCs), half of which had been pulsed with a recall $\mathrm{Ag}$, whereas the other half carried a control Ag. The preferential disappearance from the cocultures of viable DCs bearing the recall $\mathrm{Ag}$ served as a measure of NK-cellmediated Ag-specific cytotoxicity.

The source of material for such cell-based assays to assess NK cell memory is critical. For example, Ag-specific memory NK cells (other than those recognizing MCMV via Ly49H) in mice are restricted to a liver-resident Thy $1^{+}$ CXCR6 $^{+}$subset (Paust et al. 2010). CXCR6 ${ }^{+}$ NK cells are very rare in murine spleen and peripheral blood, and NK cells from these compartments show no detectable recall activity in mice (O’Leary et al. 2006; Paust et al. 2010). By contrast, in nonhuman primates, Ag-specific memory NK cells are present in both liver and spleen, but peripheral blood NK cells show minimal Ag-specific recall activity (Reeves et al. 
Is There Natural Killer Cell Memory and Can It Be Harnessed by Vaccination?

2015). In humans, like in mice, $\mathrm{CXCR}^{+} \mathrm{NK}$ cells are detectable in the liver, but very sparse among circulating NK cells (Stegmann et al. 2016). It is still unclear whether human adaptive memory NK cells exist and whether they require CXCR6; however, a recent study has identified a tissue-resident noncirculating NK cell subset in human liver that is characterized by the absence of CD49e (Aw Yeang et al. 2017). It is not known whether these cells have the capacity to form Ag-specific memory like their counterparts in mice and primates. Nonetheless, our experience in animals raises the possibility that peripheral blood NK cells are inadequate to detect vaccine Ag-specific memory NK cells in humans. On the other hand, it is likely that some vaccines, particularly live vectors or adjuvanted formulations containing Toll-like receptor (TLR) agonists, elicit cytokine responses during the priming phase that may generate nonspecific NK cell memory. Enhanced responses by such NK cells could potentially be used for longitudinal studies in humans; however, a greater abundance of cytokine-sensitized NK cells could potentially also result in increased background activity in assays aimed at detecting Ag-specific NK cells, rendering the detection of adaptive NK cell memory even more difficult.

Even in the event that future experiments are successful at identifying vaccine-induced memory NK cells, it may be challenging to determine the degree to which protection against subsequent infections is mediated by NK cells relative to other adaptive immune cells. This question is more straightforward to address in mice because we can vaccinate mutant animals that possess NK cells, but not B and/or T cells, and we can also use strategies to selectively deplete NK cells in immunized animals or perform adoptive transfers of purified NK cell subsets from vaccinated to naïve hosts (O'Leary et al. 2006; Sun et al. 2009; Paust et al. 2010; Gillard et al. 2011). However, none of these experimental manipulations are applicable to humans, whereas vaccines will usually generate responses not only by (presumably) NK cells, but also by B and $\mathrm{T}$ cells.

Related to the above discussion, it is also important to consider how prophylactic vac- cines that produce NK cell memory could be evaluated for their clinical efficacy. Traditionally, vaccine efficacy has been assessed by comparing the incidence of infection in vaccine recipients and a placebo control group. This strategy is well suited for vaccines that elicit neutralizing antibodies that prevent or minimize clinically detectable infections (or de novo immune responses against incipient infections), a process referred to as "sterilizing immunity." However, whereas antibodies can detect epitopes displayed on pathogens before microbial invasion of host tissues, there is no evidence that memory NK cells can detect or respond to free pathogens. The available experimental data suggest that infection of host cells must occur before recall responses by memory NK cells are elicited on Ag presentation by infected host cells. Thus, it is questionable whether protection by memory NK cells (or memory T cells for that matter) in the absence of protective antibodies could manifest as "sterilizing immunity." Cell-mediated protection against infectious diseases would more likely result in accelerated pathogen clearance and reduced morbidity or mortality.

Similar diagnostic challenges may also be encountered when vaccines are used to stimulate NK cells therapeutically (e.g., to combat chronic infections or cancer). To date, the focus in the field has been primarily on $\mathrm{T}$ cells, particularly the $\mathrm{CD}^{+}$subset, which can effectively eliminate diseased cells presenting cognate Ag in the context of major histocompatibility complex (MHC) class I (Appay et al. 2008; Koup and Douek 2011; Morvan and Lanier 2016). However, NK cells have long been recognized as playing an important role in cancer biology as well (Morvan and Lanier 2016). To date, the role of NK cells in immuno-oncology has been primarily studied in the context of their innate immune function, such as through recognition of target cells that lack MHC class I ("missing self") and/ or express ligands for activating NK receptors (Waldhauer and Steinle 2008; Kijima et al. 2011). However, recent findings in a mouse model of hapten-induced Ag-specific NK responses against melanocyte-associated Ags suggest that adaptive NK cells may also contribute to antitumor immunity (van den Boorn et al. 
H.R. Neely et al.

2016). Of note, distinct NK cell subsets have been observed to differ in their tumoricidal activity, with hepatic NK cells displaying more potent antitumor effects than splenic or bloodborne NK cells (Vermijlen et al. 2002; Ishiyama et al. 2006). Thus, for a concise analysis of therapeutic vaccine effects in patients, it may be necessary to monitor NK cells in a variety of samples, including biopsies and/or surgical explants of affected tissues.

A related question is whether endogenous responses of a patient's NK cells against chronic infections or malignancies may be boosted by therapeutic interventions. Indeed, NK cells in tumor-bearing mice and in patients with advanced melanoma have been reported to acquire an exhausted phenotype (Gill et al. 2012; da Silva et al. 2014). This raises the possibility for NKcell-targeted immunotherapy with "checkpoint inhibitors," whereby NK cell exhaustion may be pharmacologically reversed (e.g., by blockade of coinhibitory receptors, such as Tim-3). Recent clinical findings have shown that checkpoint inhibitors that target the CTLA4 or PD-1 pathway can unleash potent antitumor responses by exhausted T cells in some cancer patients (Curran et al. 2010; Jiang et al. 2015). Animal studies lend support to the notion that combination treatment with biologics that reverse T-cell exhaustion and vaccines that stimulate Ag-specific immune responses can exert potent synergistic effects in cancer therapy (Duraiswamy et al. 2013). It is tempting to speculate that analogous strategies could also promote NK-cell-mediated antitumor responses, but this idea remains to be validated.

\section{ACKNOWLEDGMENTS}

This work is supported by the Harvard Medical School Center for Immune Imaging and $\mathrm{Na}$ tional Institutes of Health (NIH)/National Institute of Allergy and Infectious Diseases (NIAID) Grants P01 AI112521 and R01 AI11595 (to U.H.v.A). C.G. is supported by a postdoctoral fellowship from the Cancer Research Institute Irvington Fellowship Program, and by the Rubicon Fellowship from the Netherlands Organization for Scientific Research (NWO). H.R.N. is supported by NIH/NIAID Institutional Training Grant T32 AI007512.

\section{REFERENCES}

Abdul-Careem MF, Lee AJ, Pek EA, Gill N, Gillgrass AE, Chew MV, Reid S, Ashkar AA. 2012. Genital HSV-2 infection induces short-term NK cell memory. PLoS ONE 7: e32821.

Appay V, Douek DC, Price DA. 2008. CD8 ${ }^{+}$T cell efficacy in vaccination and disease. Nat Med 14: 623-628.

Aw Yeang HX, Piersma SJ, Lin Y, Yang L, Malkova ON, Miner C, Krupnick AS, Chapman WC, Yokoyama WM. 2017. Cutting edge: Human CD49e ${ }^{-}$NK cells are tissue resident in the liver. J Immunol 198: 1417-1422.

Béziat V, Dalgard O, Asselah T, Halfon P, Bedossa P, Boudifa A, Hervier B, Theodorou I, Martinot M, Debré P, et al. 2012. CMV drives clonal expansion of NKG2C ${ }^{+}$NK cells expressing self-specific KIRs in chronic hepatitis patients Eur J Immunol 42: 447-457.

Björkström NK, Lindgren T, Stoltz M, Fauriat C, Braun M, Evander M, Michaëlsson J, Malmberg KJ, Klingström J, Ahlm C, et al. 2011. Rapid expansion and long-term persistence of elevated NK cell numbers in humans infected with hantavirus. J Exp Med 208: 13-21.

Björkström NK, Ljunggren HG, Michaelsson J. 2016. Emerging insights into natural killer cells in human peripheral tissues. Nat Rev Immunol 16: 310.

Brunetta E, Fogli M, Varchetta S, Bozzo L, Hudspeth KL, Marcenaro E, Moretta A, Mavilio D. 2010. Chronic HIV 1 viremia reverses NKG2A/NKG2C ratio on natural killer cells in patients with human cytomegalovirus co-infection. AIDS 24: 27-34.

Cerwenka A, Lanier LL. 2016. Natural killer cell memory in infection, inflammation and cancer. Nat Rev Immunol 16: 112.

Cooper MA, Elliott JM, Keyel PA, Yang L, Carrero JA, Yokoyama WM. 2009. Cytokine-induced memory-like natural killer cells. Proc Natl Acad Sci 106: 1915.

Curran MA, Montalvo W, Yagita H, Allison JP. 2010. PD-1 and CTLA-4 combination blockade expands infiltrating T cells and reduces regulatory $\mathrm{T}$ and myeloid cells within $\mathrm{B} 16$ melanoma tumors. Proc Natl Acad Sci 107: 4275-4280.

da Silva IP, Gallois A, Jimenez-Baranda S, Khan S, Anderson AC, Kuchroo VK, Osman I, Bhardwaj N. 2014. Reversal of NK-cell exhaustion in advanced melanoma by Tim-3 blockade. Cancer Immunol Res 2: 410-422.

Della Chiesa M, Falco M, Muccio L, Bertaina A, Locatelli F, Moretta A. 2013. Impact of HCMV infection on NK cell development and function after HSCT. Front Immunol 4: 458.

Della Chiesa M, Falco M, Bertaina A, Muccio L, Alicata C, Frassoni F, Locatelli F, Moretta L, Moretta A. 2014. Human cytomegalovirus infection promotes rapid maturation of NK cells expressing activating killer Ig-like receptor in patients transplanted with $\mathrm{NKG}_{2} \mathrm{C}^{-1-}$ umbilical cord blood. J Immunol 192: 1471-1479.

Dou Y, Fu B, Sun R, Li W, Hu W, Tian Z, Wei H. 2015. Influenza vaccine induces intracellular immune memory of human NK cells. PLoS ONE 10: e0121258. 
Duraiswamy J, Kaluza KM, Freeman GJ, Coukos G. 2013. Dual blockade of PD-1 and CTLA-4 combined with tumor vaccine effectively restores $\mathrm{T}$-cell rejection function in tumors. Cancer Res 73: 3591-3603.

Foley B, Cooley S, Verneris MR, Pitt M, Curtsinger J, Luo X, Lopez-Vergès S, Lanier LL, Weisdorf D, Miller JS. 2012. Cytomegalovirus reactivation after allogeneic transplantation promotes a lasting increase in educated $\mathrm{NKG}_{2} \mathrm{C}^{+}$ natural killer cells with potent function. Blood 119: 2665 2674.

Fu X, Liu Y, Li L, Li Q, Qiao D, Wang H, Lao S, Fan Y, Wu C. 2011. Human natural killer cells expressing the memoryassociated marker CD45RO from tuberculous pleurisy respond more strongly and rapidly than $\mathrm{CD}^{2} 5 \mathrm{RO}^{-}$natural killer cells following stimulation with interleukin- 12 . Immunology 134: 41-49.

Fu X, Yu S, Yang B, Lao S, Li B, Wu C. 2016. Memory-like antigen-specific human NK cells from TB pleural fluids produced IL-22 in response to IL-15 or Mycobacterium tuberculosis antigens. PLoS ONE 11: e0151721.

Gill S, Vasey AE, De Souza A, Baker J, Smith AT, Kohrt HE, Florek M, Gibbs KD Jr, Tate K, Ritchie DS, et al. 2012. Rapid development of exhaustion and down-regulation of eomesodermin limit the antitumor activity of adoptively transferred murine natural killer cells. Blood 119: 57585768.

Gillard GO, Bivas-Benita M, Hovav AH, Grandpre LE, Panas MW, Seaman MS, Haynes BF, Letvin NL. 2011. Thy1 ${ }^{+}$NK cells from vaccinia virus-primed mice confer protection against vaccinia virus challenge in the absence of adaptive lymphocytes. PLoS Pathog 7: e1002141.

Habib S, El Andaloussi A, Hisham A, Ismail N. 2016. NK cell-mediated regulation of protective memory responses against intracellular ehrlichial pathogens. PLOS ONE 11: e0153223.

Herberman RB, Nunn ME, Holden HT, Lavrin DH. 1975. Natural cytotoxic reactivity of mouse lymphoid cells against syngeneic and allogeneic tumors. II: Characterization of effector cells. Int J Cancer 16: 230.

Ishiyama K, Ohdan H, Ohira M, Mitsuta H, Arihiro K, Asahara T. 2006. Difference in cytotoxicity against hepatocellular carcinoma between liver and periphery natural killer cells in humans. Hepatology 43: 362-372.

Jamieson AM, Isnard P, Dorfman JR, Coles MC, Raulet DH. 2004. Turnover and proliferation of NK cells in steady state and lymphopenic conditions. J Immunol 172: 864.

Jiang Y, Li Y, Zhu B. 2015. T-cell exhaustion in the tumor microenvironment. Cell Death Dis 6: e1792.

Kiessling R, Klein E, Pross H, Wigzell H. 1975. "Natural" killer cells in the mouse. II: Cytotoxic cells with specificity for mouse Maloney leukemia cells. Characteristics of the killer cell. Eur J Immunol 5: 118.

Kijima M, Gardiol N, Held W. 2011. Natural killer cell mediated missing-self recognition can protect mice from primary chronic myeloid leukemia in vivo. PLoS ONE 6: e27639.

Koup RA, Douek DC. 2011. Vaccine design for CD8 T lymphocyte responses. Cold Spring Harb Perspect Med 1: a007252.

Lanier LL. 2005. NK cell recognition. Annu Rev Immunol 23: 225.
Lee J, Zhang T, Hwang I, Kim A, Nitschke L, Kim M, Scott JM, Kamimura Y, Lanier LL, Kim S. 2015. Epigenetic modification and antibody-dependent expansion of memory-like NK cells in human cytomegalovirusinfected individuals. Immunity 42: 431-442.

Li T, Wang J, Wang Y, Chen Y, Wei H, Sun R, Tian Z. 2017. Respiratory influenza virus infection induces memory-like liver NK cells in mice. J Immunol 198: $1242-1252$.

Lopez-Vergès S, Milush JM, Schwartz BS, Pando MJ, Jarjoura J, York VA, Houchins JP, Miller S, Kang SM, Norris PJ, et al. 2011. Expansion of a unique CD57 ${ }^{+} \mathrm{NKG} 2 \mathrm{C}^{\text {hi }}$ natural killer cell subset during acute human cytomegalovirus infection. Proc Natl Acad Sci 108: 14725-14732.

Majewska-Szczepanik M, Paust A, von Andrian UH, Askenase PW, Szczepanik M. 2013. Natural killer cell-mediated contact sensitivity develops rapidly and depends on interferon- $\alpha$, interferon- $\gamma$ and interleukin-12. Immunology 140: 98.

Middleton D, Gonzelez F. 2010. The extensive polymorphism of KIR genes. Immunology 129: 8.

Milush JM, López-Vergès S, York VA, Deeks SG, Martin JN Hecht FM, Lanier LL, Nixon DF. 2013. CD56 ${ }^{\text {neg }} \mathrm{CD} 16^{+}$ NK cells are activated mature NK cells with impaired effector function during HIV-1 infection. Retrovirology 10: 158 .

Morvan MG, Lanier LL. 2016. NK cells and cancer: You can teach innate cells new tricks. Nat Rev Cancer 16: 7.

O'Leary JG, Goodarzi M, Drayton DL, von Andrian UH. 2006. T cell- and B cell-independent adaptive immunity mediated by natural killer cells. Nat Immunol 7: 507.

O'Sullivan TE, Sun JC, Lanier LL. 2015. Natural killer cell memory. Immunity 43: 634.

Paust S, von Andrian UH. 2011. Natural killer cell memory. Nat Immunol 12: 500.

Paust S, Gill HS, Wang BZ, Flynn MP, Moseman EA, Senman B, Szczepanik M, Telenti A, Askenase PW, Compans RW, et al. 2010. Critical role for the chemokine receptor CXCR6 in NK cell-mediated antigen-specific memory of haptens and viruses. Nat Immunol 11: 1127-1135.

Petitdemange C, Becquart P, Wauquier N, Béziat V, Debré P, Leroy EM, Vieillard V. 2011. Unconventional repertoire profile is imprinted during acute chikungunya infection for natural killer cells polarization toward cytotoxicity. PLoS Pathog 7: e1002268.

Prlic M, Blazar BR, Farrar MA, Jameson SC. 2003. In vivo survival and homeostatic proliferation of natural killer cells. J Exp Med 197: 967.

Rabacal W, Pabbisetty SK, Hoek KL, Centron D, Guo Y, Maseda D, Sebzda E. 2016. Transcription factor KLF2 regulates homeostatic NK cell proliferation and survival. Proc Natl Acad Sci 113: 5370-5375.

Ranson T, Vosshenrich CA, Corcuff E, Richard O, Müller W, Di Santo JP. 2003. IL-15 is an essential mediator of peripheral NK-cell homeostasis. Blood 101: 4887-4893.

Reeves RK, Li H, Jost S, Blass E, Li H, Schafer JL, Varner V, Manickam C, Eslamizar L, Altfeld M, et al. 2015. Antigenspecific NK cell memory in rhesus macaques. Nat Immunol 16: 927-932. 
H.R. Neely et al.

Rolle A, Pollmann J, Cerwenka A. 2013. Memory of infections: An emerging role for natural killer cells. PLoS Pathog 9: e1003548.

Romee R, Schneider SE, Leong JW, Chase JM, Keppel CR, Sullivan RP, Cooper MA, Fehniger TA. 2012. Cytokine activation induces human memory-like NK cells. Blood 120: $4751-4760$.

Romee R, Maximillian R, Berrien-Elliott MM, Wagner JA, Jewell BA, Schappe T, Leong JW, Schneider SE, Willey S, Fehniger TA. 2015. Human cytokine-induced memorylike NK cells exhibit in vivo anti-leukemia activity in xenografted NSG mice and in patients with acute myeloid lukemia (AML). Blood 126: 101.

Rouzaire P, Luci C, Blasco E, Bienvenu J, Walzer T, Nicolas JF, Hennino A. 2012. Natural killer cells and T cells induce different types of skin reactions during recall responses to haptens. Eur J Immunol 42: 80-88.

Schenkel AR, Kingry LC, Slayden RA. 2013. The ly49 gene family. A brief guide to the nomenclature, genetics, and role in intracellular infection. Front Immunol 4: 90.

Schlums H, Cichocki F, Tesi B, Theorell J, Beziat V, Holmes TD, Han H, Chiang SC, Foley B, Mattsson K, et al. 2015 Cytomegalovirus infection drives adaptive epigenetic diversification of NK cells with altered signaling and effector function. Immunity 42: 443-456.

Simonetta F, Pradier A, Roosnek E. 2016. T-bet and eomesodermin in NK cell development, maturation, and function. Front Immunol 7: 241.

Sojka DK, Tian Z, Yokoyama WM. 2014. Tissue-resident natural killer cells and their potential diversity. Semin Immunol 26: 127.

Spits H, Artis D, Colonna M, Diefenbach A, Di Santo JP, Eberl G, Koyasu S, Locksley RM, McKenzie AN, Mebius RE, et al. 2013. Innate lymphoid cells-A proposal for uniform nomenclature. Nat Rev Immunol 13: 145149.
Spits H, Bernink JH, Lanier L. 2016. NK cells and type 1 innate lymphoid cells: Partners in host defense. Nat Immunol 17: 758 .

Stegmann KA, Robertson F, Hansi N, Gill U, Pallant C, Christophides T, Pallett LJ, Peppa D, Dunn C, Fusai G, et al. 2016. CXCR6 marks a novel subset of T-bet ${ }^{\text {lo }}$ Eomes ${ }^{\text {hi }}$ natural killer cells residing in human liver. $\mathrm{Sci}$ Rep 6: 26157.

Sun JC, Beilke JN, Lanier LL. 2009. Adaptive immune features of natural killer cells. Nature 457: 557.

Sun JC, Beilke JN, Bezman NA, Lanier LL. 2011. Homeostatic proliferation generates long-lived natural killer cells that respond against viral infection. J Exp Med 208: 357.

Sung H, Schleiss MR. 2010. Update on the current status of cytomegalovirus vaccines. Expert Rev Vaccines 9: 1303.

Thornthwaite JT, Leif RC. 1974. The plaque cytogram assay. I: Light and scanning electron microscopy of immunocompetent cells. J Immunol 113: 1897.

van den Boorn JG, Jakobs C, Hagen C, Renn M, Luiten RM, Melief CJ, Tüting T, Garbi N, Hartmann G, Hornung V. 2016. Inflammasome-dependent induction of adaptive NK cell memory. Immunity 44: 1406-1421.

Vermijlen D, Luo D, Froelich CJ, Medema JP, Kummer JA, Willems E, Braet F, Wisse E. 2002. Hepatic natural killer cells exclusively kill splenic/blood natural killer-resistant tumor cells by the perforin/granzyme pathway. J Leukoc Biol 72: 668-676.

Waldhauer I, Steinle A. 2008. NK cells and cancer immunosurveillance. Oncogene 27: 5932.

York VA, Milush J, Lopez-Verges S, Deeks S, Martin J, Hecht F, Lanier L, Nixon D. 2013. CD $56^{\text {neg }} C D 16^{+}$NK cells are mature NK cells generated from $\mathrm{CD} 56^{+} \mathrm{CD} 16^{+} \mathrm{NK}$ cells during HIV-1 infection (P4438). J Immunol 190: 206.6.

Yu J, Freud AG, Caligiuri MA. 2013. Location and cellular stages of natural killer cell development. Trends Immunol 34: 573 . 


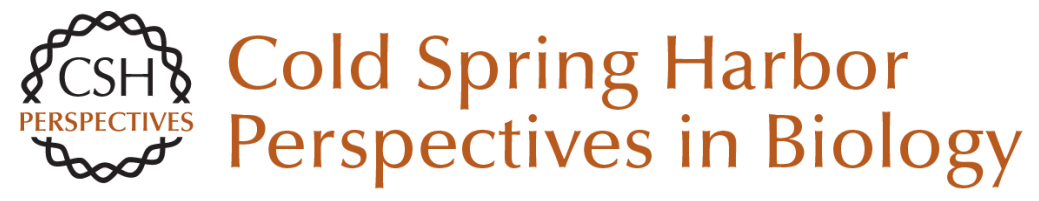

\title{
Is There Natural Killer Cell Memory and Can It Be Harnessed by Vaccination?: Natural Killer Cells in Vaccination
}

\author{
Harold R. Neely, Irina B. Mazo, Carmen Gerlach and Ulrich H. von Andrian
}

Cold Spring Harb Perspect Biol 2018; doi: 10.1101/cshperspect.a029488 originally published online December 18, 2017

Subject Collection Immune Memory and Vaccines: Great Debates

Is There Natural Killer Cell Memory and Can It Be Harnessed by Vaccination?: Can Natural Killer and CD8 T Cells Switch Jobs?

Christine A. Biron and Marcus Altfeld

Is There Natural Killer Cell Memory and Can It Be Harnessed by Vaccination?: Vaccination Strategies Based on NK Cell and ILC Memory Megan A. Cooper, Todd A. Fehniger and Marco Colonna

Is It Possible to Develop Cancer Vaccines to Neoantigens, What Are the Major Challenges, and How Can These Be Overcome?: Neoantigens as Vaccine Targets for Cancer Haydn T. Kissick

Is It Possible to Develop Cancer Vaccines to Neoantigens, What Are the Major Challenges, and How Can These Be Overcome?: Neoantigens: Nothing New in Spite of the Name

Olivera J. Finn and Hans-Georg Rammensee

Which Dengue Vaccine Approach Is the Most Promising, and Should We Be Concerned about Enhanced Disease after Vaccination?: The Challenges of a Dengue Vaccine

Gavin Screaton and Juthathip Mongkolsapaya
Is There Natural Killer Cell Memory and Can It Be Harnessed by Vaccination?: NK Cell Memory and Immunization Strategies against Infectious Diseases and Cancer Joseph C. Sun and Lewis L. Lanier

Is There Natural Killer Cell Memory and Can It Be Harnessed by Vaccination?: Natural Killer Cells in Vaccination

Harold R. Neely, Irina B. Mazo, Carmen Gerlach, et al.

Is It Possible to Develop Cancer Vaccines to Neoantigens, What Are the Major Challenges, and How Can These Be Overcome?: Targeting the Right Antigens in the Right Patients Stephen P. Schoenberger

Which Dengue Vaccine Approach Is the Most Promising, and Should We Be Concerned about Enhanced Disease after Vaccination?: There Is Only One True Winner Scott B. Halstead

Which Dengue Vaccine Approach Is the Most Promising, and Should We Be Concerned about Enhanced Disease after Vaccination?: Questions Raised by the Development and Implementation of Dengue Vaccines: Example of the Sanofi Pasteur Tetravalent Dengue Vaccine Bruno Guy

For additional articles in this collection, see http://cshperspectives.cshlp.org/cgi/collection/

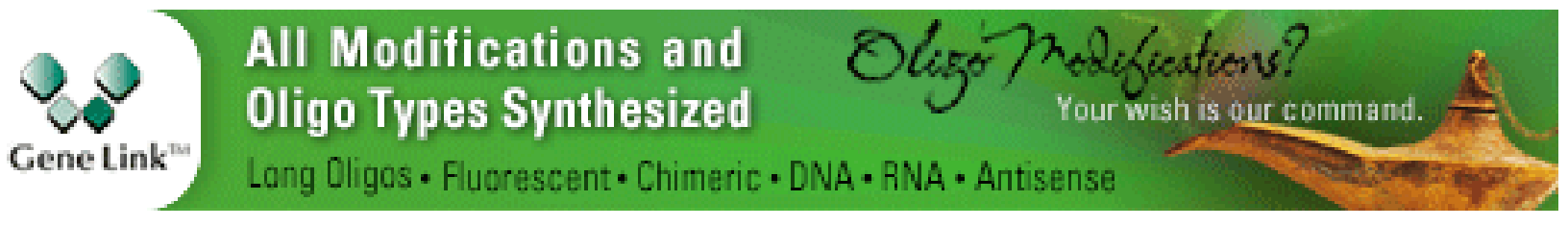


Which Dengue Vaccine Approach Is the Most Promising, and Should We Be Concerned about Enhanced Disease after Vaccination?: The Path to a Dengue Vaccine: Learning from Human Natural Dengue Infection Studies and Vaccine Trials Aravinda M. de Silva and Eva Harris

Is It Possible to Develop a "Universal" Influenza Virus Vaccine?: Potential for a Universal Influenza Vaccine

James E. Crowe, Jr.

Is It Possible to Develop a "Universal" Influenza Virus Vaccine?: Outflanking Antibody Immunodominance on the Road to Universal Influenza Vaccination

Davide Angeletti and Jonathan W. Yewdell
Which Dengue Vaccine Approach Is the Most Promising, and Should We Be Concerned about Enhanced Disease after Vaccination?: The Risks of Incomplete Immunity to Dengue Virus Revealed by Vaccination

Stephen S. Whitehead and Kanta Subbarao

Is It Possible to Develop a "Universal" Influenza Virus Vaccine?: Immunogenetic Considerations Underlying B-Cell Biology in the Development of a Pan-Subtype Influenza A Vaccine Targeting the Hemagglutinin Stem

Sarah F. Andrews, Barney S. Graham, John R. Mascola, et al.

Is It Possible to Develop a "Universal" Influenza Virus Vaccine?: Potential Target Antigens and Critical Aspects for a Universal Influenza Vaccine Florian Krammer, Adolfo García-Sastre and Peter Palese

For additional articles in this collection, see http://cshperspectives.cshlp.org/cgi/collection/

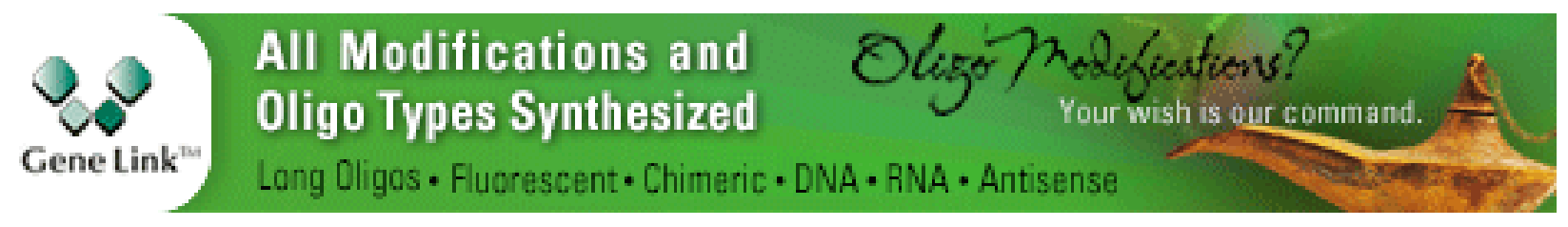

Copyright @ 2018 Cold Spring Harbor Laboratory Press; all rights reserved 